\title{
Variation of the Content of Ethyl Esters in Extra Virgin Olive Oils during Their Shelf Life
}

\author{
María A. Grompone, Nicolás Callejas, Natalia Martínez, Camila Feller, Miguel Amarillo and Bruno A. Irigaray \\ Laboratorio de Grasas y Aceites, Facultad de Química (UDELAR), Av. Gral. Flores 2124, Montevideo, Uruguay
}

\begin{abstract}
Fatty acids' ethyl and methyl esters are not natural components of edible vegetable oils and therefore should not be present in virgin olive oils. Among the quality requirements for extra virgin olive oils, the International Olive Council (IOC) Norm, 2015 review, set limits for the ethyl ester content at $\leq 435 \mathrm{ppm}$ for the 2014/2015 and 2015/2016 harvests and at $\leq 30 \mathrm{ppm}$ for the 2016/2017 harvest. The purpose of this paper is to: (a) determine the alkyl ester content in two extra virgin olive oils (of the Arbequina and Coratina varieties) as parameters of quality at the moment of their elaboration and to assess the length of their shelf life, over a 12 month period at room temperature; (b) determine extra virgin olive oils' free alcohols content as these may esterify due to the free fatty acids present during storage. After 6 months of storage, the Arbequina oil's ethyl ester content was $32 \mathrm{ppm}$, and the Coratina's was $46 \mathrm{ppm}$. As a result, the shelf life for both was only about half a year (labeling usually indicates it must be consumed "before 1 year"). However, parameters related to oxidation (peroxide index, K 232, K 270 and $\Delta \mathrm{K}$ ) remained within the limits set by the International Olive Council (IOC) throughout the year. In conclusion: ethyl ester content is a very fine parameter for assessing the quality of extra virgin in an olive oil and determining the length of its shelf life.
\end{abstract}

Key words: Alkyl esters, free alcohols, olive oil, shelf life.

\section{Introduction}

In literature there are several studies on the shelf life of virgin olive oils [1-8]. Most of them determine the length of the shelf life depending on the variation of the acidity and/or rates of oxidation and/or changes in the content of antioxidants. There are also assays on accelerated storage conditions $[9,10]$.

None of these papers takes the formation of alkyl esters during storage into consideration.

Fatty acid methyl and ethyl esters are not natural components of vegetable oils, therefore, should not present in virgin olive oils $[11,12]$. So that they appear, should have previously free methanol and ethanol in the oil. This is only possible through some kind of fermentation of the carbohydrates present in olives. Later on, a transesterification of the triglycerides or esterification of the free fatty acids with such alcohols should occur. As a consequence, the presence of these esters in extra virgin olive oil

Corresponding author: Bruno Irigaray, Ph.D., research fields: fats and oils. could indicate a poor treatment of the olives as a cause for the fermentation $[13,14]$.

If virgin olive oils contain methanol and ethanol during their elaboration process, these will gradually esterify with the free fatty acids causing the corresponding esters. As this process is relatively slow, an increase in the content of alkyl esters and decrease of the free alcohols should occur during storage [15]. These reactions are independent of the oil oxidative degradation.

The International Oil Council (IOC) Norm [16] has established, among its quality requirements for extra virgin olive oils, limits for the content of ethyl esters: $\leq 35 \mathrm{ppm}$ for the $2014 / 2015$ and 2015/2016 harvests and $\leq 30 \mathrm{ppm}$ for the $2016 / 2017$ harvest.

Therefore, the purpose of this paper is to determine the alkyl ester content in extra virgin olive oils as quality parameters at the moment of elaboration and to assess the length of their shelf life. On the other hand, the content of free alcohols in extra virgin olive oil was determined as these may be esterified by the free 
fatty acids present during storage.

\section{Materials and Methods}

\subsection{Samples}

Extra virgin olive oils, of the Arbequina and Coratina variety, of industrial elaboration and from the same Uruguayan mill were analyzed. These varieties were chosen for being the most cultivated in Uruguay.

Four imported extra virgin olive oils (one from Argentina, at the beginning of its shelf life, one from Spain, at the end of its shelf life, and two from Italy in the middle of their shelf life) were also analyzed.

Shelf life of the oils: Two monovarietal Arbequina and Coratina extra virgin olive oils, of Uruguayan industrial production were stored in $100 \mathrm{~mL}$ capped amber glass bottles over a 12 month period, in an oven at $30{ }^{\circ} \mathrm{C}$. This temperature was selected because it is about room temperature in the summer in Uruguay. Every month or every 3 months one bottle was removed from the oven and the oil analyzed; the remaining oil was discarded.

\subsection{Analytical Techniques}

Determination of the methyl and ethyl ester content: method COI/T.20/Doc. $\mathrm{n}^{\mathrm{o}}$. 28 "Determination of the content of waxes and methyl and ethyl esters content of the fatty acids through chromatography of gases with capillary column" [17].

Determination of free methane and ethane content: according to the method of Gómez-Coca et al. [18].

Peroxide Index: method AOCS Cd 8b-90 [19].

Ultraviolet Absorption: method AOCS CH 5-91 [19].

All determinations were performed in duplicate.

\section{Results and Discussion}

Fig. 1 shows the evolution of methyl esters (EM), and ethyl esters (EE) content (ppm) in Arbequina and Coratina olive oils over the storage period (months) at room temperature. The evolution of the sum of both is also shown. At the time of packaging, Arbequina oil contained $34.9 \mathrm{ppm}$ of ethyl esters and Coratina oil contained $21.6 \mathrm{ppm}$. During storage, the methyl ester content increased much more slowly than the content of ethyl esters, causing the total amount of alkyl esters to be, principally, determined by the content of ethyl esters. The Norm from the International Olive Council (IOC), in its 2015 review, allows a maximum of 35 ppm, meaning the Arbequina oil, since the beginning, was at the limit allowed.

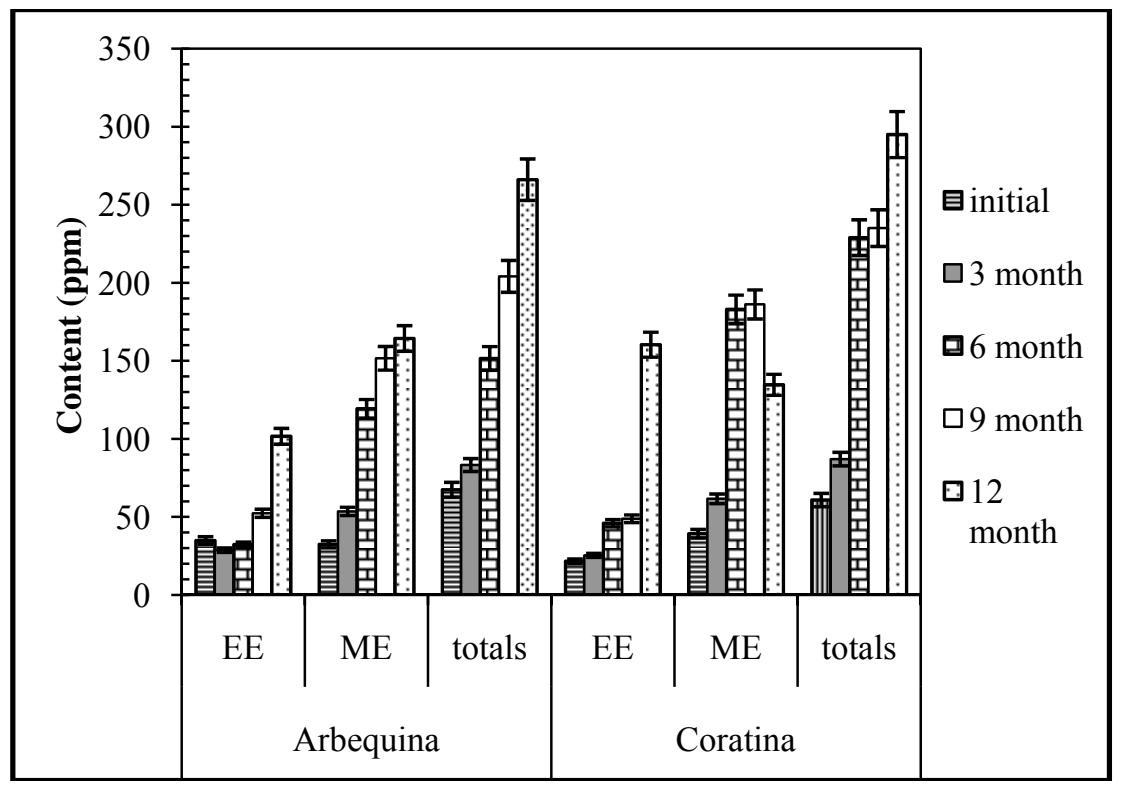

Fig. 1 Evolution of the content (ppm) of methyl ester (ME), ethyl ester (EE) and the addition of both, over the storage period. 
After 6 months, the ethyl ester content for the Arbequina oil was $32.3 \mathrm{ppm}$, and $46.0 \mathrm{ppm}$ for the Coratina oil. As a consequence, the life of both lasted about half a year (labeling usually indicated "best before 1 year"). On the other hand, after 9 months of storage there was a significant acceleration in the formation of ethyl esters in both oils, the reason for this is unknown.

The quality parameter values associated with oxidation (peroxide index and ultraviolet absorption index) are shown on Table 1. After 6 months of storage, all these quality parameters did not exceed the limits set by the IOC 2015. This is not in accordance with the ethyl ester content which surpassed the corresponding IOC 2015 limits.

The formation of methyl and ethyl esters in the oil is caused by the esterification of free methanol and ethanol with the free fatty acids (acidity). The oxidation of the oils during storage is different from the esterification of free alcohols, hence, both parameters may be independent: not just in relation to their initial values, but also their evolution over time.

In order to complement this study on the storage of two Uruguayan oils, imported oils were analyzed at different stages of its life. Thereby, it is possible to confirm whether the formation of ethyl esters also appears in them. Table 2 shows the results of some purity and quality parameters for the four imported oils. The values that did not comply with the 2015 IOC Norm are presented in grey. These results confirm that the formation of ethyl esters is a problem of virgin olive oils packaged and not just a casual problem of two Uruguayan oils studied.

Considering their ultraviolet absorption, (K232, $\mathrm{K} 270$ and $\Delta \mathrm{K}$ ) two of the four oils in the study failed to comply with the 2015 IOC requirements to be considered extra virgin. Two oils exceeded the standard IOC limits for the content of waxes but only one

Table 1 Variation of peroxide and ultraviolet absorption indexes over the storage period.

\begin{tabular}{lllllllllll}
\hline Months & 0 & 1 & 2 & 3 & 4 & 5 & 6 & 9 & 10 & IOC 2015 \\
\hline Arbequina oil & & & & & & & & & \\
\hline $\begin{array}{l}\text { Peroxide } \\
\text { index }\end{array}$ & $4.1 \pm 0.2$ & $5.3 \pm 0.3$ & $6.8 \pm 0.4$ & $6.8 \pm 0.4$ & $7.8 \pm 0.4$ & $8.0 \pm 0.4$ & $6.8 \pm 0.4$ & $10.4 \pm 0.5$ & $7.6 \pm 0.3$ & $\leq 20$ \\
K232 & $1.80 \pm 0.09$ & $1.99 \pm 0.10$ & $2.14 \pm 0.10$ & $2.12 \pm 0.10$ & $2.05 \pm 0.10$ & $2.18 \pm 0.10$ & $2.19 \pm 0.10$ & $2.17 \pm 0.10$ & $2.35 \pm 0.10$ & $\leq 2.50$ \\
K270 & $0.11 \pm 0.01$ & $0.16 \pm 0.01$ & $0.12 \pm 0.01$ & $0.11 \pm 0.01$ & $0.10 \pm 0.01$ & $0.15 \pm 0.01$ & $0.14 \pm 0.01$ & $0.11 \pm 0.01$ & $0,20 \pm 0.01$ & $\leq 0.22$ \\
$\Delta \mathrm{K}$ & 0.00 & 0.00 & 0.00 & 0.00 & 0.00 & 0.00 & 0.00 & -0.01 & 0.001 & $\leq 0.01$ \\
\hline Coratina oil & & & & & & & & & \\
\hline Peroxide & $4.9 \pm 0.2$ & $5.7 \pm 0.3$ & $6.4 \pm 0.3$ & $8.3 \pm 0.4$ & $7.8 \pm 0.4$ & $6.7 \pm 0.3$ & $8.3 \pm 0.4$ & $8.6 \pm 0.4$ & $7.0 \pm 0.3$ & $\leq 20$ \\
index & 1.43 & 1.78 & 1.46 & 1.49 & 1.97 & 2.11 & 2.01 & 1.82 & 2.12 & $\leq 2.50$ \\
K232 & $0.16 \pm 0.01$ & $0.20 \pm 0.01$ & $0.16 \pm 0.01$ & $0.14 \pm 0.01$ & $0.16 \pm 0.01$ & $0.18 \pm 0.01$ & $0.17 \pm 0.01$ & $0.17 \pm 0.01$ & $0.26 \pm 0.01$ & $\leq 0.22$ \\
K270 & 0.01 & 0.00 & 0.00 & 0.00 & 0.00 & 0.00 & 0.00 & 0.01 & 0.00 & $\leq 0.01$ \\
\hline K & & & & & & & & &
\end{tabular}

Table 2 Some purity and quality parameters for four imported extra virgin olive oils, in accordance with the 2015 IOC Norm.

\begin{tabular}{|c|c|c|c|c|c|c|}
\hline & & Italy 1 & Italy 2 & Spain & Argentina & IOC 2015 \\
\hline \multicolumn{2}{|l|}{ K232 } & $1.96 \pm 0.10$ & $2.42 \pm 0.13$ & $2.22 \pm 0.11$ & $2.34 \pm 0.12$ & $<2.5$ \\
\hline \multicolumn{2}{|l|}{$\mathrm{K} 270$} & $0.15 \pm 0.01$ & $0.28 \pm 0.02$ & $0.27 \pm 0.02$ & $0.16 \pm 0.01$ & $\leq 0.22$ \\
\hline \multicolumn{2}{|l|}{$\Delta \mathrm{K}$} & 0.00 & 0.01 & 0.01 & 0.00 & $\leq 0.01$ \\
\hline \multicolumn{2}{|l|}{$\Delta \mathrm{ECN} 42$} & $0.11 \pm 0.01$ & $0.05 \pm 0.01$ & $0.08 \pm 0.01$ & $0.12 \pm 0.01$ & $\leq 0.2$ \\
\hline \multirow{2}{*}{ Waxes (ppm) } & without $\mathrm{C} 40$ & 0 & $834 \pm 58$ & $47 \pm 5$ & $705 \pm 49$ & $\leq 150$ extra \\
\hline & with C40 & $21 \pm 5$ & $875 \pm 60$ & $94 \pm 8$ & $727 \pm 50$ & $\leq 250$ ordinary \\
\hline \multicolumn{2}{|c|}{ Methyl esters (ME) ppm (ppm) } & $44 \pm 3$ & $158 \pm 8$ & $18 \pm 3$ & $89 \pm 4$ & \\
\hline \multicolumn{2}{|c|}{ Ethyl esters (EE) ppm } & $88 \pm 5$ & $91 \pm 5$ & $110 \pm 6$ & $51 \pm 3$ & $\leq 35$ \\
\hline \multicolumn{2}{|c|}{ Addition of ME and EE (ppm) } & $132 \pm 17$ & $249 \pm 26$ & $128 \pm 28$ & $140 \pm 15$ & $<75$ \\
\hline
\end{tabular}


of these two oils coincided with the previous two. It is interesting to notice the high content of wax for two of the olive oils as they should have been labeled as olive-pomace oil as the 2015 IOC Norm allows a wax content greater than $350 \mathrm{ppm}$ for this.

The four oils presented very small quantities of free alcohols: between $8.1 \mathrm{ppm}$ and $23.3 \mathrm{ppm}$ for methanol and between $1.6 \mathrm{ppm}$ and $15.9 \mathrm{ppm}$ for ethanol. However, the amounts of alkyl esters present were far superior: between $18 \mathrm{ppm}$ and $158 \mathrm{ppm}$ for methyl esters and between 51 and 110 for ethyl esters. None of the four oils complies with the maximum established by the 2015 IOC Norm for ethyl esters in extra virgin olive oils (in spite of being labeled as such). The Argentinian oil was at the beginning of its shelf life, both Italian oils were in the middle of their shelf life, and the one from Spain, at the end of its shelf life.

In Table 2 the content of EE is shown for the four oils imported (oils are ordered according to increasing amounts of EE): this order coincides with the moment of the shelf life in which they were analyzed. These results coincide with the general behavior observed during the storage of the Uruguayan Arbequina and Coratina oils.

The values obtained for Uruguayan Arbequina oils and Coratina oils at the time of packaging are also indicated in Table 1. The values for these were far lower than those of the four imported oils available in the Uruguayan market.

\section{Conclusions}

Ethyl ester content is a quality parameter required by the 2015 IOC Norm for extra virgin olive oils. This paper shows its importance because oils that meet the quality parameters linked to oil oxidation (peroxide index and ultraviolet absorption), exceed the maximum content of ethyl esters. It is a contribution to the debate currently taking place in the IOC about the importance of controlling this parameter to limit the quality extra virgin.

\section{Acknowledgments}

This paper was financed by the Research Commission (CSIC) of the University of the Republic.

\section{References}

[1] Psomiadou, E., and Tsimidou, M. 2002. "Stability of Virgin Olive Oil. 1. Autoxidation Studies." J. Agric. Food Chem. 50: 716-21.

[2] Vekiari, S. A., Papadopoulou, P., and Koutsaftakis, A. 2002. "Comparison of Different Olive Oil Extraction Systems and the Effect of Storage Conditions on the Quality of the Virgin Olive Oil." Grasas y Aceites 53 (3): 324-9.

[3] Morelló, J. R., Motilva, M. J., Tovar, M. J., and Romero, M. P. 2004. "Changes in Commercial Virgin Olive Oil (cv Arbequina) during Storage, with Special Emphasis on the Phenolic Fraction." Food Chem. 85: 357-64.

[4] Gómez-Alonso, S., Mancebo-Campos, V., Salvador, M. D., and Fregapane, G. 2005. "Evolution of Major and Minor Componentes and Oxidation Índices of Virgin Olive Oil during 21 Months Storage at Room Temperature." Food Chem. 100: 36-42.

[5] Del Caro, A., Vacca, V., Poiana, M., Fenu, P., and Piga, A. 2006. "Influence of Technology, Storage and Exposure on Componentes of Extra Virgin Olive Oil (Bosanacv) from Whole and De-Stoned Fruits." Food Chem. 98: 311-6.

[6] Méndez, M. I., and Falqué, E. 2007. "Effect of Storage Time and Container Type on the Quality of Extra-Virgin Olive Oil." Food Control 18: 521-9.

[7] Mancebo-Campos, V., Fregapane, G., and Salvador, M. D. 2008. "Kinetic Study for the Development of an Accelerated Oxidative Stability Test to Estimate Virgin Olive Oil Potential Shelf Life.” Eur. J. Lipid Sci. Technol. 110: 969-76.

[8] Mancebo-Campos, V., Salvador, M. D., and Fregapane, G. 2007. "Comparative Study of Virgin Olive Oil Behavior under Rancimat Accelerated Oxidation Conditions and Long-Term Room Temperature Storage." J. Agric. Food Chem. 55: 8231-6.

[9] Hrncirik, K., and Fritsche, A. 2005. "Relation between the Endogenous Antioxidant System and the Quality of Extra Virgin Olive Oil under Accelerated Storage Conditions." J. Agric. Food Chem. 53: 2103-10.

[10] Lerma-García, M. J., Simó-Alfonso, E., Chiavaro, E., Bendini, A., Lercker, G., and Cerretani, L. 2009. "Study of Chemical Changes Produced in Virgin Olive Oils with Different Phenolic Contents during an Accelerated Storage Treatment." J. Agric. Food Chem. 57: 7834-40.

[11] Gómez-Coca, R. B., Moreda, W., and Pérez-Camino, M. 
C. 2012. "Fatty Acid Alkyl Esters Presence in Olive Oil vs. Organoleptic Assesment." Food Chem. 135: 1205-9.

[12] Jabeur, H., Zribi, A., Abdelhedi, R., and Bouaziz, M. 2015. "Effect of Olive Storage Conditions on Chemlali Olive Oil Quality and the Effective Role of Fatty Acids Alkyl Esters in Checking Olive Oils Authenticity." Food Chem. 169: 289-96.

[13] Beltrán, G., Bejaoui, M. A., Jimenez, A., and Sanchez-Ortiz, A. 2015. "Ethanol in Olive Fruit. Changes during Ripening.” J. Agric. Food Chem. 63: 5309-12.

[14] Pérez-Camino, M. del C., Cert, A., Romero-Segura, A., Cert-Trujillo, R., and Moreda, W. 2008. "Alkyl Esters of Fatty Acids A Useful Tool to Detect Soft Deodorized Olive Oils." J. Agric. Food Chem. 56: 6740-4.

[15] Gómez-Coca, R. B., Fernandes, G. D., Pérez-Camino, M. del C., and Moreda,W. 2016. "Fatty Acid Ethyl Esters
(FAEE) in Extra Virgin Olive Oil: A Case Study of A Quality Parameter." LWT-Food Sci. Technol. 66: 378-83.

[16] COI (Consejo Oleícola Internacional). Norma comercial aplicable a los aceites de oliva y los aceites de orujo de oliva.COI/T.15/NC n ${ }^{\circ}$ 3/Rev. 9.-junio 2015.

[17] Consejo Oleícola Internacional (COI). Chemistry/Testing Methods/Chemical Testing Methods. http://www.internationaloliveoil.org/.

[18] Gómez-Coca, R. B., Cruz-Hidalgo, R., Fernandes, G. D., Pérez-Camino, M. C., and Moreda, W. 2014. "Analysis of Metanol and Etanol in Virgin Olive Oil." MethodsX (1): 207-11.

[19] AOCS. 1990. "Official Methods and Recommended Practices of the American Oil Chemists' Society." edited by Walker, R. E., In American Oil Chemists' Society, 4th edition. Champaign. 